\title{
Imaging Improves Efficacy of Vertebroplasty - A Systematic Review and Meta-Analysis
}

\author{
Jai Jai Shiva Shankar (iD, Roah Merdad, Stefanos Finitsis, Robin Parker
}

\begin{abstract}
Background: Clinical trials with percutaneous vertebral augmentation (PVA) for intractable pain from vertebral compression fractures (VCF) have shown variable results. Variation in the outcomes may be related to poor patient selection on imaging. Objective: To assess if PVA augmentation for osteoporotic VCF results in better improvement in pain when patients were selected based on clinical examination plus imaging vs clinical examination only. Results: A systematic review and meta-analysis were performed. PubMed, Embase and Cochrane Library databases were searched from 2000 to May 2018. Two reviewers independently screened and extracted data to identify randomised control trials (RCTs) on PVA for osteoporotic VCF and assessed the risk of bias. Standard systematic review and meta-analysis methods were advocated by the Cochrane Collaboration and PRISMA Statement. A total of 12 RCTs with 1110 participants met the inclusion criteria. Eight of the 10 studies (938 participants) that used imaging to confirm oedema in the target vertebral bodies showed PVA (compared to nonsurgical treatment) was effective in reducing pain (immediate term: mean difference (MD) of -1.89 ; $95 \%$ confidence interval -1.93 to $-1.85, p<0.001$; short term: $\mathrm{MD}$ of $-1.68 ; 95 \% \mathrm{CI}-1.82$ to -1.54 , $p<0.001$; intermediate term: MD of $-2.04 ; 95 \% \mathrm{CI}-2.15$ to $-1.94, p<0.001$ and long term: $\mathrm{MD}$ of $-1.88 ; 95 \% \mathrm{CI}-1.95$ to -1.80 , $p<0.001)$. Conclusions: RCTs using imaging to confirm marrow oedema in the index vertebra showed an improved size effect compared to RCTs using no imaging. This benefit was observed in the immediate, short, intermediate and long term.
\end{abstract}

RÉSUMÉ: Améliorer l'efficacité de la vertébroplastie au moyen de l'imagerie médicale : une revue systématique et une méta-analyse. Contexte : Des essais cliniques au cours desquels on a fait appel aux techniques percutanées de la vertébroplastie (vertebral augmentation) pour soulager des douleurs réfractaires produites par des fractures vertébrales par compression (FVC) ont donné à voir des résultats variables. Cette variabilité pourrait être liée à une mauvaise sélection des participants au moyen d'examens d'IRM. Objectif : Évaluer dans quelle mesure la vertébroplastie entraîne un soulagement accru de la douleur dans le cas de patients aux prises avec des FVC d'origine ostéoporotique. On a ainsi voulu comparer des patients choisis en fonction d'un examen clinique et d'un examen d'IRM avec d'autres patients choisis en fonction d'un seul examen clinique. Résultats : Nous avons mené une revue systématique ainsi qu'une méta-analyse. Pour ce faire, nous avons effectué des recherches dans les bases de données suivantes : PubMed, Embase et Cochrane, et ce, de l'année 2000 au mois de mai 2018. Deux examinateurs indépendants ont ensuite extrait et passé au crible des données afin d'identifier les essais cliniques randomisés (ECR) portant sur la vertébroplastie dans le cas de FVC d'origine ostéoporotique et d'évaluer les risques de biais. À noter que notre revue systématique et notre méta-analyse ont été effectuées en tenant compte des méthodes recommandées par Cochrane et PRISMA. Au total, douze ECR incluant 1110 participants ont satisfait à nos critères de sélection. Sur 10 ECR (938 participants) dans lesquels on a recouru à un examen d'IRM pour confirmer la présence d'un œdème dans les corps vertébraux ciblés, 8 d'entre eux ont révélé que le recours à la vertébroplastie était plus efficace qu'un traitement non-chirurgical dans le soulagement de la douleur (sur le champ : écart moyen de -1,89; IC $95 \%-1,93$ à $-1,85$; $\mathrm{p}<0,001$; à court terme : écart moyen de $-1,68$; IC $95 \%-1,82$ à $-1,54 ; \mathrm{p}<0,001$; à moyen terme : écart moyen de $-2,04 ;$ IC $95 \%$-2,15 à -1,94; $\mathrm{p}<0,001$; et à long terme : écart moyen de $-1,88 ;$ IC $95 \%-1,95$ à -1,80; $\mathrm{p}<0,001$ ). Conclusions : En somme, les ECR utilisant des examens d'IRM pour confirmer la présence d'œdèmes de la moelle épinière dans une vertèbre de référence (index vertebra) ont révélé une taille d'effet améliorée si on les compare à des ECR n'utilisant pas ces examens. Cet avantage a été observé sur le champ mais aussi à court, moyen et long terme.

Keywords: Vertebroplasty, Osteoporosis, Fractures, Vertebral compression and imaging

doi:10.1017/cjn.2019.236

Can J Neurol Sci. 2019; 46: 540-549

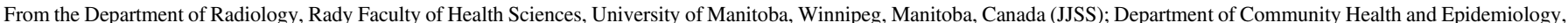

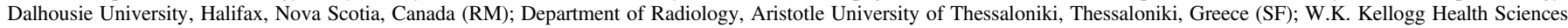
Library, School of Information Management, Dalhousie University, Halifax, Nova Scotia, Canada (RP)

Received March 12, 2019. Final Revisions Submitted June 7, 2019. Date of Acceptance June 15, 2019

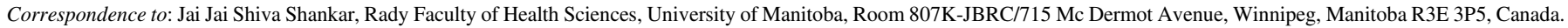
Email: shivajai1@gmail.com 


\section{INTRODUCTION}

Vertebral compression fractures (VCF) are the most common type of osteoporotic fractures resulting in chronic disabling back pain. ${ }^{1}$ These fractures are associated with significant rates of morbidity and mortality ${ }^{2}$, and an annual direct medical expenditures of more than $\$ 37$ million in $\mathrm{Canada}^{3}$ and $\$ 1$ billion in the USA. Although many patients respond favourably to nonsurgical care of their VCF, more than $40 \%$ of them fail to achieve significant pain relief by 12 months. ${ }^{2}$ After a trial of conservative pain management, many of these patients can be treated with percutaneous vertebral augmentation (PVA). There are two primary approaches to PVA - vertebroplasty and kyphoplasty that are used to hasten symptom resolution and return of function. $^{4,5}$

Two studies comparing vertebroplasty to a controversial sham control group concluded that the effect of the treatment was due to a placebo effect. ${ }^{6,7}$ Despite multiple methodological flaws, ${ }^{8-11}$ these three studies have negatively affected the practice of PVAs. One of the important limitations of patient selection was lack of imaging as inclusion criteria in two of them, ${ }^{6}$ since clinical examination does not exclude other sources of back pain, particularly when associated with chronic VCF. Bone scan as well as magnetic resonance imaging (MRI) show marrow oedema as evidence of active inflammation in the VCF. On MRI, short-TI inversion recovery (STIR) sequence is best to show marrow oedema as STIR nulls the signal from marrow fat, making the oedema more conspicuous. Active inflammation on imaging along with focal tenderness at the same level on clinical examination increases the likelihood of VCF as the source of back pain. Variation in the outcome from vertebroplasty trials may be related to poor patient selection by some of the trials. Confirming marrow oedema/active inflammation on imaging may allow these patients to get the maximum benefit from PVAs. Despite the recognition of the lack of imaging in selection criteria as an important study design flaw, this has not been examined in a systematic review. A Cochrane review in 2015 highlighted patient selection based solely on clinical criteria of the presence of back pain and duration of pain. ${ }^{12}$ The purpose of our study was to perform a systematic review of the published literature to synthesise the evidence on the efficacy of PVA in VCF patients, when selected based on clinical examination plus imaging confirmation compared to when selected solely on clinical examination. We hypothesised that imaging confirmation of marrow oedema will result in higher pain reduction from vertebroplasty compared with when imaging was not used for patient selection.

\section{Methods}

We used standard systematic review and meta-analysis methods advocated by the Cochrane Collaboration and PRISMA (Preferred Reporting Items for Systematic Reviews and MetaAnalyses) Statement. ${ }^{13-15}$ The systematic review was registered to the PROSPERO register, registration number: CRD42017071533.

Randomised controlled trials (RCT) selecting patients based on clinical examination only were compared with RCTs selecting patient based on imaging confirmation of marrow oedema as well as clinical examination to assess the efficacy of PVAs in osteoporotic VCF. A change of score by at least 1.5 on visual analogue scale (VAS) was considered minimum important change in pain. $^{16}$
Table 1: Key words used for the search strategy of electronic databases

Randomised controlled trials published anytime till June 2017 using the following search strategy for PubMed and adapted for Embase

- (randomised controlled trial[pt]

- OR controlled clinical trial[pt]

- OR random*[tiab]

- OR placebo[tiab]

- OR drug therapy[sh]

- OR trial[tiab]

- OR “drug therapy”[tiab])))

- AND ("kyphoplasty"[MeSH Terms]

- OR kyphoplast*[tiab]

- OR vertebroplasty[MH]

- OR vertebroplast*[tiab]

- OR vertebral augmentation[tiab]

- NOT animal*[tiab])

For Cochrane Library

- kyphoplast*:ti,ab,kw

- or kyphoplast*:ti,ab,kw

• or "vertebral augmentation":ti,ab,kw

\section{Inclusion Criteria}

Study type: RCTs of any design were included.

Patient type: RCTs that enrolled patients of any age with the diagnosis of painful osteoporotic VCFs of any duration.

Intervention: RCTs that compared either vertebroplasty or kyphoplasty for the treatment of osteoporotic VCFs compared to the usual care or placebo or sham procedure.

Outcome measures: Mean pain score measured by VAS.

Follow-up period: Efficacy of PVAs was defined as a change in VAS from baseline at immediate-term $(<30$ days, weighted towards 7 days), short-term ( 1 month to $<3$ months, weighted towards 1 month), intermediate-term ( 3 months to $<6$ months, weighted towards 3 months) and long-term (6 months to 12 months, weighted towards 6 months) follow-up.

Publication types: Search was unrestricted, but non-English language studies were excluded from the final review and meta-analysis. This was mainly due to lack of resources for translation. All publications on RCTs from across the world were included. Only study articles published in the peer-reviewed literature were included.

Exclusion criteria: Any study with quasi-randomised method of allocation, such as by alternation or by date of birth, was excluded. Studies on PVA were done for indications other than osteoporotic VCF such as acute trauma or oncologic fractures. Non-English language studies were also excluded.

Search strategy: A computerised search of PubMed, Embase and Cochrane Library was done using index terms and keywords (Table 1). No time filter was used for publication date. In addition to online database searching, reference lists of all included studies and previous reviews were also screened. Some of these studies were published after the last Cochrane review ${ }^{12}$; and thus, our systematic review filled an important gap. 
Data collection and analysis: Two researchers independently used Covidence for the primary and secondary screening (title/ abstract and full text, respectively) and data extraction to streamline the production of standard intervention reviews. The titles and abstracts were screened and were categorised as 'Yes', 'No' and 'Maybe'. For those categorised as 'Yes' and 'Maybe', a full text review was done to assess the inclusion of the studies. Data were then extracted from the included studies using a standard extraction form with characteristics of the trials, participants, interventions and outcomes. The data were only extracted from intention to treat analysis.

Covidence was also used for risk of bias assessment using Cochrane risk of bias criteria. Cochrane risk of bias criteria included assessment of sequence generation; allocation concealment; blinding of participants and study personnel; blinding of outcome assessors; incomplete outcome data, selective outcome reporting and other sources of bias. Data on all relevant variables were collected.

Meta-analysis: A quantitative synthesis, supplemented by a qualitative discussion, was used for a thorough and accessible amount of the available data. For the quantitative synthesis, metaanalysis was conducted to synthesise mean difference (MD) in pain estimates between patients selected using imaging and clinical examination vs those selected only on clinical examination. The efficacy of PVA for these two groups was calculated using a fixed effects generic inverse variance meta-analysis. The Cochrane Collaboration statistical software, Review manager (Revman 5.3) was used to conduct the meta-analysis, and forest plots and funnel charts were generated. Pooled estimates and $95 \%$ confidence interval (CI) were calculated in overall as well as subgroup analysis. The unit of analysis was the number of participants (and not the number of fractures).

Missing data: The studies with missing data could not be included in the meta-analysis. When the number of patients at each time points was not specified, the number of patients randomised was used for meta-analysis. For continuous outcomes, when standard deviation (SD) was not reported, SDs were calculated from standard errors, 95\% CIs or p-values using Revman calculator tool. For continuous outcomes presented only graphically, the mean and 95\% CIs were extracted from the graphs using WebPlotDigitizer (http://arohatgi.info/WebPlotDigitizer/).

Assessment of heterogeneity: The statistical heterogeneity was assessed by visually assessing the scatter of effect estimates on the forest plots, and by using the Chi-squared statistic and the $\mathrm{I}^{2}$ statistic. ${ }^{17} \mathrm{I}^{2}$ statistic was interpreted using the following as an approximate guide ${ }^{18}$ :

- $0 \%-40 \%$ may not be important heterogeneity;

- 30\%-60\% may represent moderate heterogeneity;

- 50\%-90\% may represent substantial heterogeneity and

- 75\%-100\% may represent considerable heterogeneity.

In case of considerable heterogeneity, we explored the data further with subgroup analysis.

Grading of evidence: Overall, quality of evidence was graded by interpretation of the quantitative synthesis using recommendations of the GRADE Working Group. ${ }^{19}$ The risk of bias, the completeness and context of available evidence, and the size and consistency of observed effect were considered in the grading of evidence.

\section{Results}

Our search strategy of electronic databases (Figure 1) identified a total of 1312 citations, including citations from conference proceedings. After discarding 254 duplicates, a total of 1058 citations were screened for title and abstracts (Figure 1). Of this, 90 relevant full-text articles were identified. Thirteen RCTs (2 kyphoplasty and 11 vertebroplasty RCTs) met the inclusion criteria for this review. Since there were only two kyphoplasty RCTs with no comparators, we decided to exclude them to reduce the heterogeneity. ${ }^{20,21}$

The RCTs included were conducted in Italy and other European countries, ${ }^{22}$ China, ${ }^{23,24}$ Iran, ${ }^{25}$ Spain ${ }^{26}$ Netherlands, Belgium, ${ }^{27-29}$ Australia, ${ }^{7,30}$ USA, UK, Australia ${ }^{6}$ and Denmark ${ }^{31}$ (Table 2).

A total of 12 RCTs were included in our review ${ }^{6,7,22-28,30,31}$ (Table 2). Of these, 10 used imaging (MRI or bone scan) to confirm bone oedema for patient selection ${ }^{7,22-30}$ (Figure 4). The other two RCTs did not use imaging to confirm bone oedema as for their patient selection. ${ }^{6,31}$ Of the 10 RCTs which used imaging for patient selection, 8 of them showed improvement in pain score after vertebroplasty compared to conservative/sham management. ${ }^{22-28,30}$ Only 2 of these 10 RCTs showed no improvement of pain score after vertebroplasty. ${ }^{7,29}$

A total of four RCTs showed that vertebroplasty did not result in the improvement of pain score. ${ }^{6,7,29,31}$ Out of these, two studies used imaging as inclusion criteria, ${ }^{7,29}$ the third RCT used imaging only when there was uncertainty about the age of the fractures ${ }^{6}$ and the fourth used imaging only when there were more than one level of $\mathrm{VCF}^{31}$ The latter two studies did not report imaging as their inclusion criteria and did not report the percentage of patients in which imaging was used.

Trial design: Only parallel design RCTs were included in the study. Eight of the 12 RCTs compared vertebroplasty to nonsurgical care. ${ }^{22-28,31}$ The other four RCTs compared vertebroplasty to a sham procedure. $6,7,29,30$

In studies, where crossover was allowed, the primary outcome of mean pain difference was recorded before crossover was allowed. The analysis was based on intention to treat.

Trial participants: A total of 5725 patients with osteoporotic VCF were screened in the 12 RCTs to include 1629 patients. Of 1453 patients included, 1279 (78.51\%) were female. One RCT included only female patients. ${ }^{22}$ The pain score was reported at different follow-up intervals in these RCTs. Effort was taken to include all data points reported in the RCTs for the meta-analysis. One RCT was excluded from the meta-analysis as it did not have any follow-up information to be included in the meta-analysis. ${ }^{22}$ After excluding patients from this RCT, ${ }^{21} 1110$ patients were included in the meta-analysis. Of these, 564 underwent vertebroplasty and 546 were in the control arms and received either conservative management or sham procedure. The minimum age of the participants was 50 years old. Of the 12 RCTs, 4 did not specify the age of the patients. ${ }^{7,23,25,26}$

Interventions: All RCTs included had vertebroplasty done for patients in the interventional arm. Vertebroplasty was done using either uni or bipedicular approach. Vertebroplasty was done for one to four vertebral body levels in the studies. Most studies included vertebral bodies from T5 to L5 levels. 


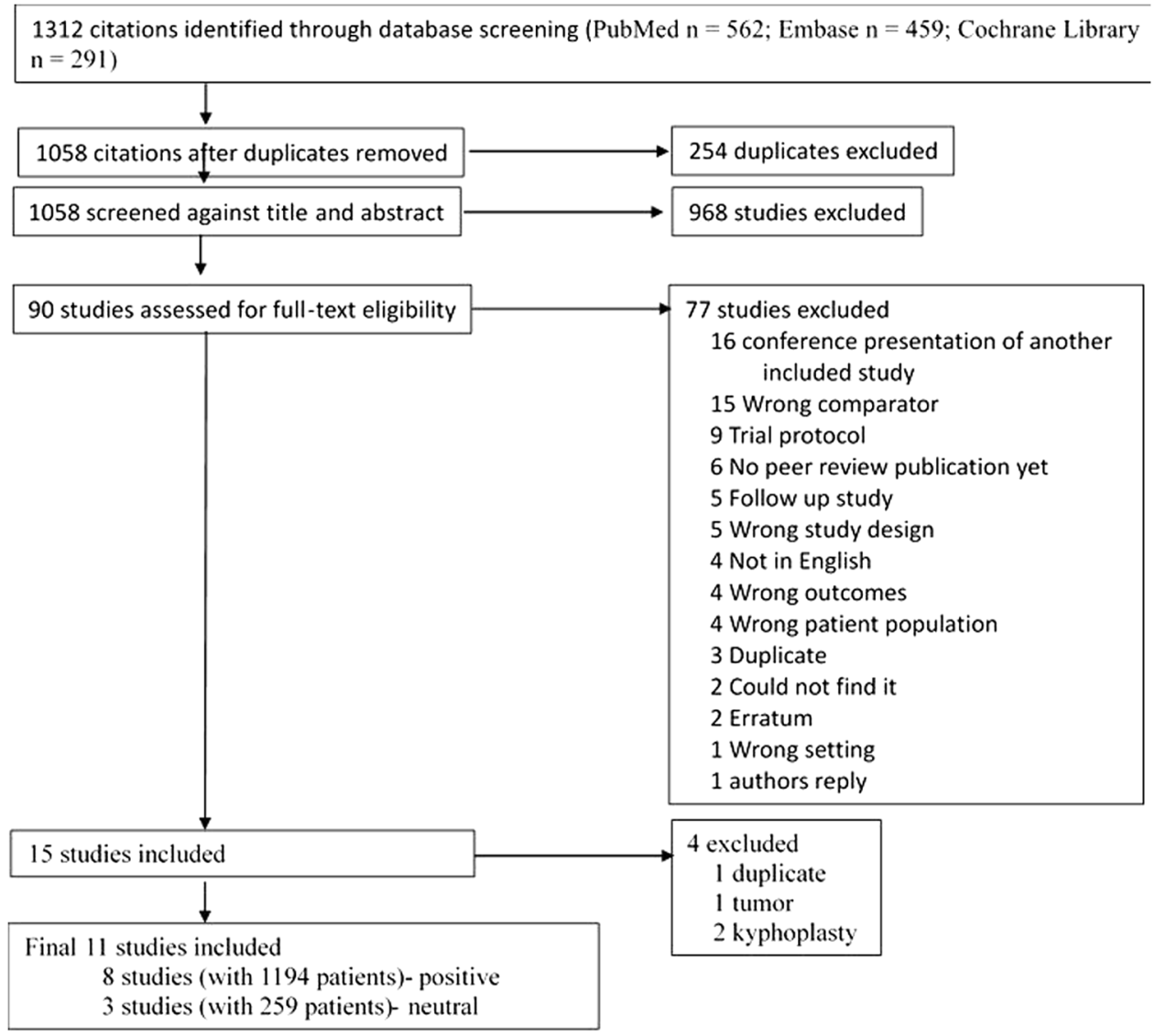

Figure 1: Flowchart of selection of studies.

For the control arm, eight RCTs used conservative management and the other four used sham procedure. ${ }^{6,7,29,30}$ Of these four RCTs with the sham control group, one found vertebroplasty beneficial in improving pain ${ }^{30}$ and the other three were neutral. ${ }^{6,7,29}$ For sham procedures, the participants underwent the same procedures as those in the vertebroplasty group up to the insertion of the 13-gauge needle to rest on the periosteum of the lamina and vertebral bodies were gently tapped in two studies. ${ }^{6,7,29}$ In one study, the periosteum was not touched. ${ }^{30}$ To simulate vertebroplasty, polymethyl methacrylate was prepared so that its smell permeated the room.

Outcome: Pain was the main outcome to test the efficacy of vertebroplasty. Most commonly used pain score was VAS on a scale of $0-10$. The RCTs varied in the duration of pain prior to patient selection. Six RCTs included patients with less than 8 weeks of symptoms. ${ }^{22,24,28-31,32}$ Six studies included patients with more than 8 weeks and up to 12 months of symptoms. ${ }^{6,7,23,25-27}$ Six of the 12 RCTs did not specify the baseline pain score as their inclusion criteria. ${ }^{12,22,23,25,27,31}$ In the other six studies, the pain score as inclusion criteria varied from three ${ }^{6}$ to seven. ${ }^{30}$ All RCTs reported pain difference on VAS. One study also used Dallas Pain Questionnaire. ${ }^{31}$

Other outcome measures included the assessment of disability and quality of life. The scales varied significantly among studies and thus were not comparable. The scales used to measure disability were Roland Morris Disability Questionnaire, Oswestry Disability Index, 36-Item Short Form Survey (SF-36) and Study of Osteoporotic Fractures Activities of Daily Living. The scales used to measure the quality of life were Quality of Life Questionnaire of the European Foundation for Osteoporosis (QUALEFFO), Mental Component Summary, European Quality of Life with 5 Dimensions (EQ-5D) and Assessment of Quality of Life. Of these, the most consistently used scale was QUALEFFO in five RCTs ${ }^{7,27-30}$ and data could be extracted from only three of these $^{7,29,30}$ and thus was not assessed in this review. Number of vertebral body fracture on follow-up, serious adverse events and treatment success rate were also inconsistently reported and were not assessed in this review.

\section{Benefits}

\section{Vertebroplasty vs Control.}

There was substantial heterogeneity between studies with I $2=96 \%-100 \%$ for the pooled estimate for all RCTs (1110 participants) (Figures 2-5). PVA was effective in reducing pain at immediate-term (MD of $-1.87 ; 95 \% \mathrm{CI}-1.91$ to -1.83 , $p<0.001$ ), short-term (MD of $-1.52 ; 95 \% \mathrm{CI}-1.65$ to -1.39 , $p<0.001$ ), intermediate-term (MD of $-2.00 ; 95 \% \mathrm{CI}-2.11$ to $-1.89, p<0.001)$ and long-term (MD of $-1.88 ; 95 \% \mathrm{CI}-1.95$ to $-1.80, p<0.001$ ) follow-up.

\section{Imaging vs No Imaging.}

Only 2 of the 12 RCTs included in this review did not have imaging specified as their inclusion criteria (Figures 2-5). 6,31 Eight of the 10 RCTs (762 participants) that used imaging to 
Table 2: Summary of all included studies

\begin{tabular}{|c|c|c|c|c|c|c|c|}
\hline & \begin{tabular}{|l} 
Imaging for \\
diagnosis
\end{tabular} & Authors & Year of publication & Country & Intervention & Number of patients & Follow-up duration \\
\hline \multirow[t]{2}{*}{1} & Yes & Firanescu et al. & 2018 & Netherlands & VP & 90 & 12 mths \\
\hline & & & & & Sham & 86 & \\
\hline \multirow[t]{2}{*}{2} & Yes & Leali et al. & 2016 & $\begin{array}{c}\text { Italy (other } \\
\text { European } \\
\text { countries) }\end{array}$ & VP & 200 & $6 \mathrm{mths}$ \\
\hline & & & & & $\mathrm{CM}$ & 200 & \\
\hline \multirow[t]{2}{*}{3} & Yes & Yang et al. & 2016 & China & VP & 66 & 12 mths \\
\hline & & & & & $\mathrm{CM}$ & 69 & \\
\hline \multirow[t]{2}{*}{4} & Yes & Farrokhi et al. & 2011 & Iran & $\mathrm{VP}$ & 40 & 36 mths \\
\hline & & & & & $\mathrm{CM}$ & 42 & \\
\hline \multirow[t]{2}{*}{5} & Yes & Blasco et al. & 2012 & Spain & VP & 64 & 12 mths \\
\hline & & & & & $\mathrm{CM}$ & 61 & \\
\hline \multirow[t]{2}{*}{6} & Yes & Chen et al. & 2014 & China & VP & 46 & 12 mths \\
\hline & & & & & $\mathrm{CM}$ & 50 & \\
\hline \multirow[t]{2}{*}{7} & Yes & Clark et al. & 2016 & Australia & VP & 61 & 6 mths \\
\hline & & & & & Sham & 59 & \\
\hline \multirow[t]{2}{*}{8} & Yes & Voormolen et al. & 2007 & Netherlands & VP & 18 & $2 \mathrm{wks}$ \\
\hline & & & & & $\mathrm{CM}$ & 16 & \\
\hline \multirow[t]{2}{*}{9} & Yes & Klazen et al. & 2010 & $\begin{array}{l}\text { Netherlands and } \\
\text { Belgium }\end{array}$ & VP & 101 & $1 \mathrm{mth}$ \\
\hline & & & & & $\mathrm{CM}$ & 101 & \\
\hline \multirow[t]{2}{*}{10} & Yes & Buchbinder et al. & 2009 & Australia & $\mathrm{VP}$ & 38 & 3 mths \\
\hline & & & & & Sham & 40 & \\
\hline \multirow[t]{2}{*}{11} & No & Kallmes et al. & 2009 & USA, UK, Australia & VP & 68 & $1 \mathrm{mth}$ \\
\hline & & & & & Sham & 63 & \\
\hline \multirow[t]{2}{*}{12} & No & Rousing et al. & 2009 & Denmark & VP & 26 & 3 mths \\
\hline & & & & & CM & 24 & \\
\hline
\end{tabular}

VP=Vertebroplasty; CM=Conservative management; US=United States; UK=United Kingdom; mth=Month.

confirm oedema in the target vertebral bodies showed PVA was effective in reducing pain at immediate-term (MD of $-1.89 ; 95 \%$ $\mathrm{CI}-1.93$ to $-1.85, p<0.001$ ), short-term (MD of $-1.52 ; 95 \%$ $\mathrm{CI}-1.65$ to $-1.39, p<0.001$ ), intermediate-term (MD of -2.04 ; $95 \% \mathrm{CI}-2.15$ to $-1.94, p<0.001$ ) and long-term (MD of -1.88 ; $95 \% \mathrm{CI}-1.95$ to $-1.80, p<0.001)$ follow-up. There was substantial heterogeneity between studies with $\mathrm{I} 2=96 \%-100 \%$ for the pooled estimate for these RCTs (1110 participants).

Two RCTs (172 participants) did not include imaging as inclusion criteria and showed PVA was not effective in reducing pain at immediate-term (MD of $0.10 ; 95 \% \mathrm{CI}-0.23$ to -0.43 , $p=0.56$ ), short-term (MD of $-0.40 ; 95 \% \mathrm{CI}-0.77$ to -0.03 , $p<0.04)$ and intermediate-term (MD of $-0.50 ; 95 \% \mathrm{CI}-0.33$ to $-1.33, p=0.24$ ) follow-up. Both of these studies did not report the long-term outcomes. One of them reported only the immediate- and short-term outcomes. ${ }^{6}$ The other reported only the intermediate-term outcome. ${ }^{31}$ The heterogeneity was not applicable to this subgroup as there was only one study available for comparison at immediate, short and intermediate term.
Risk of bias in included studies: The risk of bias was assessed for allocation, blinding, incomplete outcome data, selective reporting and other sources. The risk of bias summary for each risk of bias item for each included RCT is shown in Figure 6. This is shown in a risk of bias graph where the judgements about each risk of bias item are presented as percentages across all included studies (Figure 7). The risk of bias was used for grading the evidence from this review.

\section{Discussion}

\section{Summary of Main Results}

VCF is a common cause of chronic disabling back pain. ${ }^{1}$ Many of these patients do not respond to conservative pain management and may be treated with PVA. The evidence for PVA is debated. For the purpose of this review, a change of score by at least 1.5 on VAS was considered minimum important change. ${ }^{16}$ The pooled estimate of all included RCTs showed significant $(p<0.001)$ improvement in mean pain. 


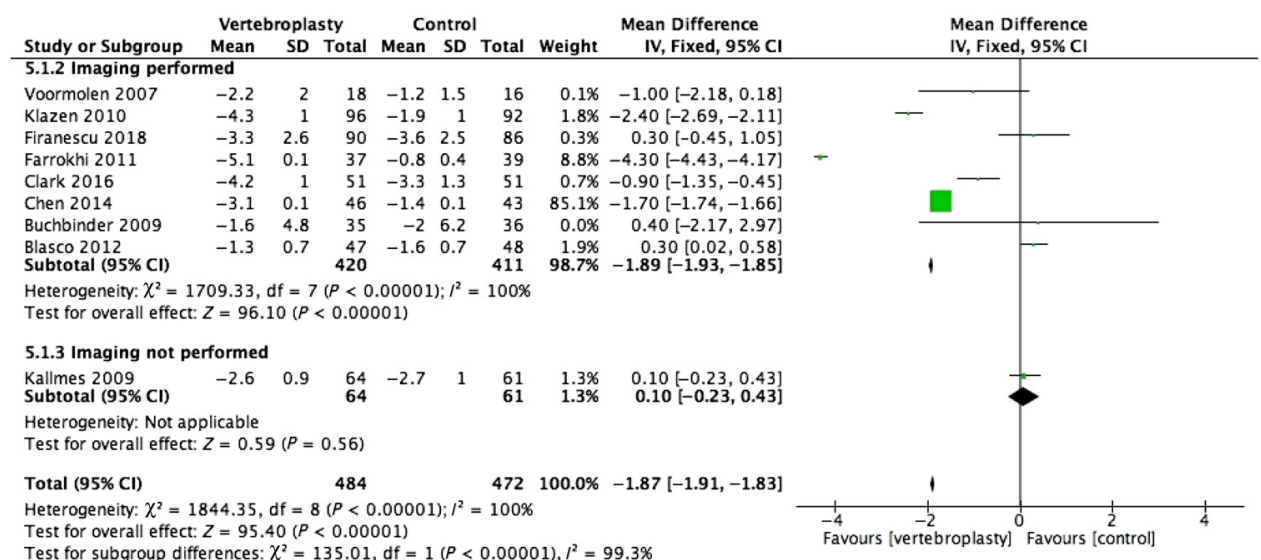

Test for subqroup differences: $\chi^{2}=135.01, \mathrm{df}=1(P<0.00001), I^{2}=99.3 \%$

Figure 2: Forest plot representing a comparison between vertebroplasty and control in the mean difference in change in pain score (visual analogue scale) from baseline at immediate-term follow-up for the subgroups: imaging performed and imaging not performed.

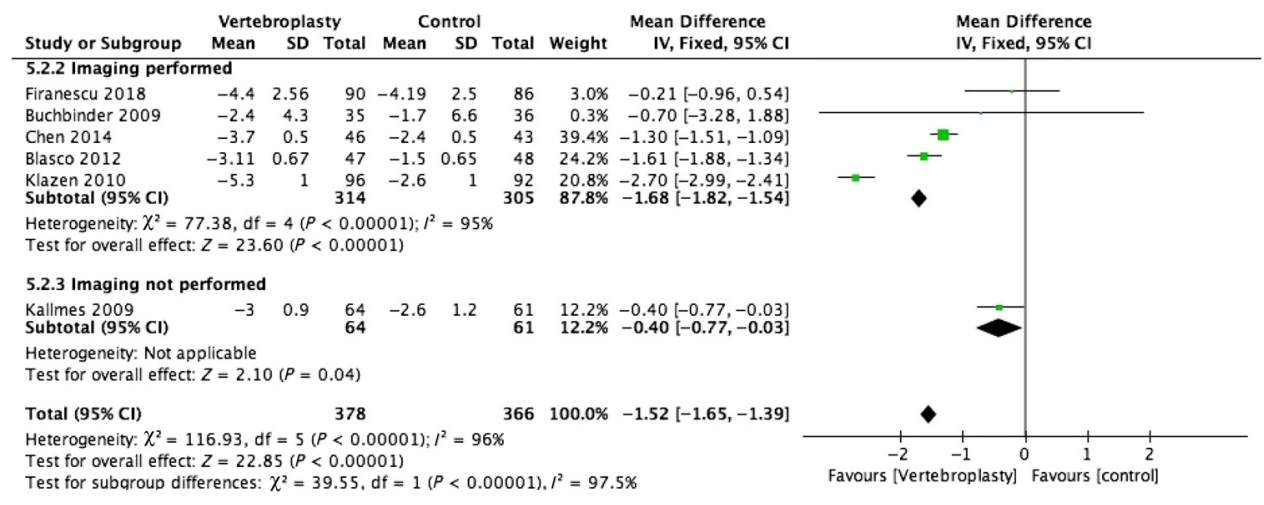

Figure 3: Forest plot representing a comparison between vertebroplasty and control in the mean difference in change in pain score (visual analogue scale) from baseline at short-term (1-3 months) follow-up for the subgroups: imaging performed and imaging not performed.

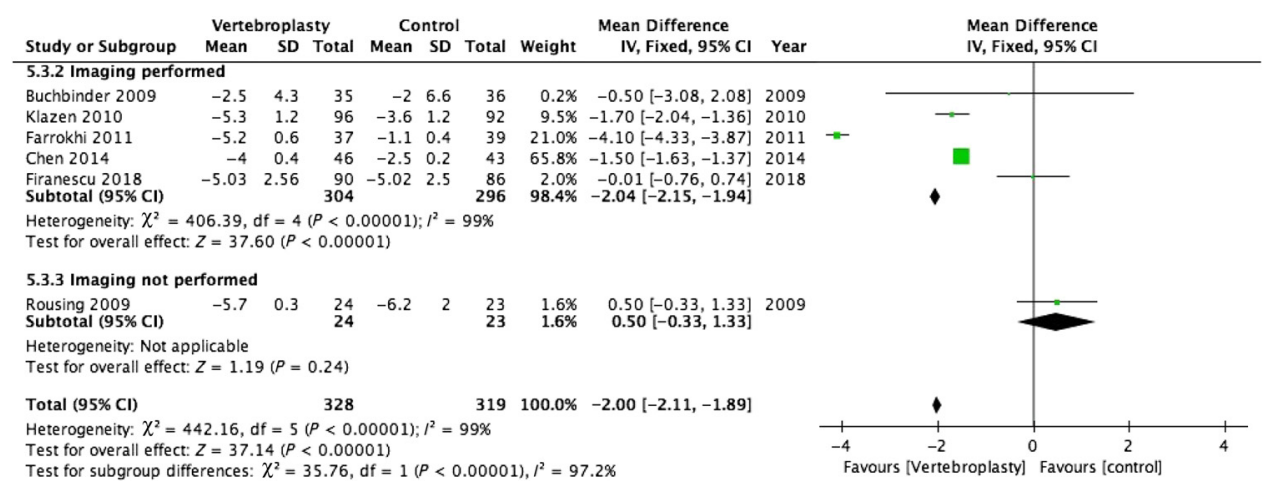

Figure 4: Forest plot representing a comparison between vertebroplasty and control in the mean difference in change in pain score (visual analogue scale) from baseline at intermediate-term (3-6 months) follow-up for the subgroups: imaging performed and imaging not performed.

Our systematic review of 12 RCTs showed that 8 of the 10 RCTs that used imaging confirmation as inclusion criteria showed benefit from vertebroplasty. The other two RCTs that did not use imaging confirmation as inclusion criteria did not show benefit from vertebroplasty. ${ }^{6,31}$ The meta-analysis was possible for data from 11 of the 12 studies. On VAS, the RCTs selecting patients on imaging showed higher efficacy in reducing pain at immediate-term (MD of $-1.89 ; 95 \% \mathrm{CI}-1.93$ to -1.85 ), short-term (MD of -1.68 ; $95 \% \mathrm{CI}-1.82$ to -1.54 ), intermediateterm (MD of $-2.04 ; 95 \% \mathrm{CI}-2.15$ to -1.94$)$ and equal efficacy 


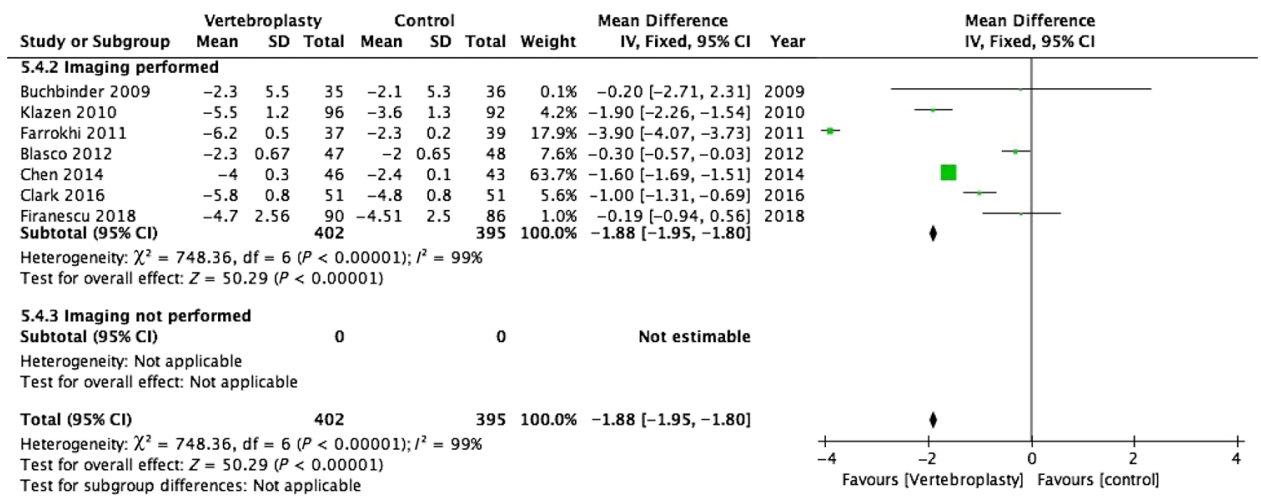

Test for subgroup differences: Not applicable

Figure 5: Forest plot representing a comparison between vertebroplasty and control in the mean difference in change in pain score (visual analogue scale) from baseline at long-term follow-up for the subgroups: imaging performed and imaging not performed.

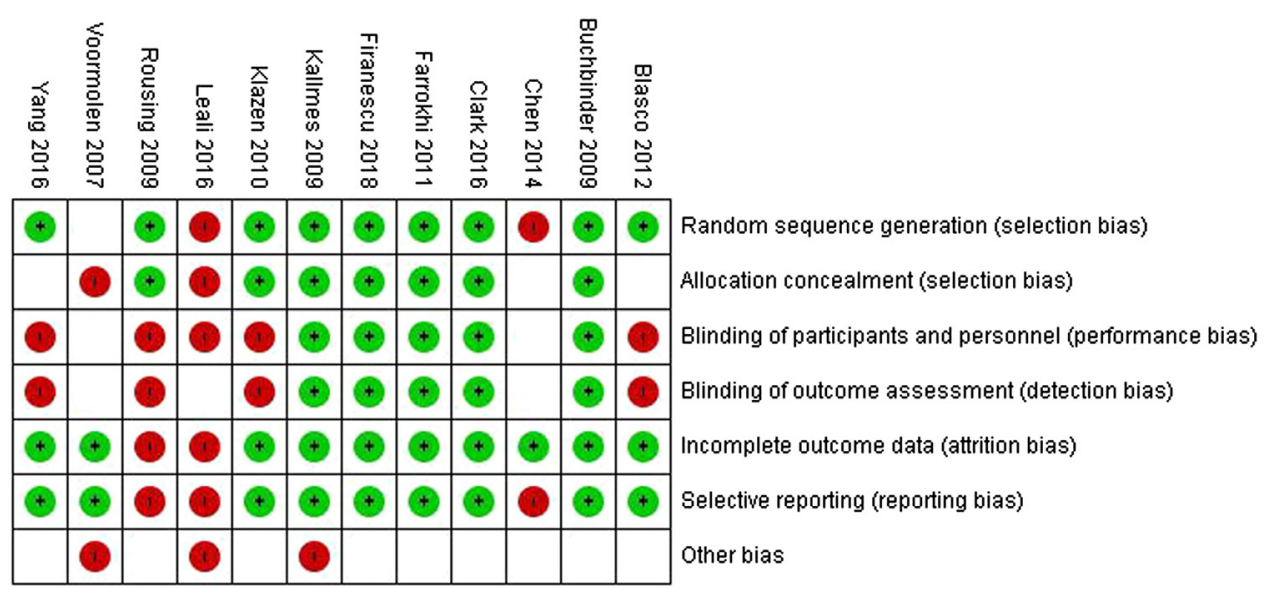

Figure 6: Risk of bias summary: judgements about each risk of bias item for each included RCT.

at long-term (MD of $-1.88 ; 95 \% \mathrm{CI}-1.95$ to -1.80 ) follow-up compared to the pooled estimates of all the trials. On the other hand, the RCTs that did not select patients on imaging showed the vertebroplasty was not effective in pain reduction at immediateterm (MD of $0.10 ; 95 \% \mathrm{CI}-0.23$ to $-0.43, p=0.56$ ), short-term (MD of $-0.40 ; 95 \% \mathrm{CI}-0.77$ to $-0.03, p<0.04$ ) and intermediate-term (MD of $-0.50 ; 95 \% \mathrm{CI}-0.33$ to $-1.33, p=0.24$ ) follow-up. At short term, even though these RCTs confirmed the efficacy of vertebroplasty, the MD of pain was only 0.4 , much lower than the threshold of 1.5 to be considered meaningful pain improvement.

This is very important information for patients suffering from chronic disabling pain. After the publication of the two sham trials in $2009^{6,7}$ and another in $2018,{ }^{29}$ there is a general perception in the physician community that vertebroplasty was proven not to be beneficial for pain relief in patients with osteoporotic VCF. The findings from our review suggest that vertebroplasty is effective for pain relief in this patient population, particularly when patients were selected with imaging confirmation of oedema.

Completeness and applicability of evidence: This review is limited as it only reviewed the evidence provided by 12 RCTs performed in different parts of the world. However, this review included all RCTs of vertebroplasty compared with conservative/ sham treatments for osteoporotic VCF that were published before
April, 2018. Vertebroplasty was compared to conservative management (in eight trials) and sham procedures (in four trials). The trials tend to report different outcome measures using different outcome scales. To reach a more homogeneous conclusion, we selected the most important purpose of vertebroplasty (i.e., pain relief) using the simple and widely used pain scale (i.e., VAS). The pain outcome was also grouped at different predetermined follow-up intervals. Given the heterogeneity in reporting of outcomes and the substantial heterogeneity of more than $95 \%$ in our review, the conclusion from our review should be cautiously used in routine clinical practice. This review highlights the need of more well-designed RCTs to confirm the efficacy of vertebroplasty, and these RCTs must include imaging confirmation of marrow oedema for selection of patients.

Quality of evidence: For our primary comparison and subgroup analysis of RCTs, the overall quality was high by GRADE approach. ${ }^{33}$ But the quality should be downgraded to moderate since some of the included studies suffered from a high risk of bias and heterogeneity (Figures 6 and 7).

Potential bias in the review process: Two reviewers independently screened all the studies to reduce any bias during the screening process. Inclusion of only studies with full publication in peer-reviewed journals led to publication bias. This was done to keep the quality of evidence to the highest possible level. Only 


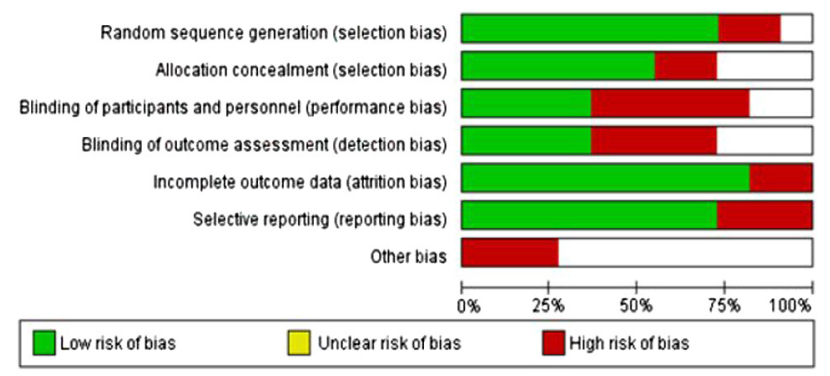

Figure 7: Risk of bias graph: judgements about each risk of bias item presented as percentages across all included RCTs.

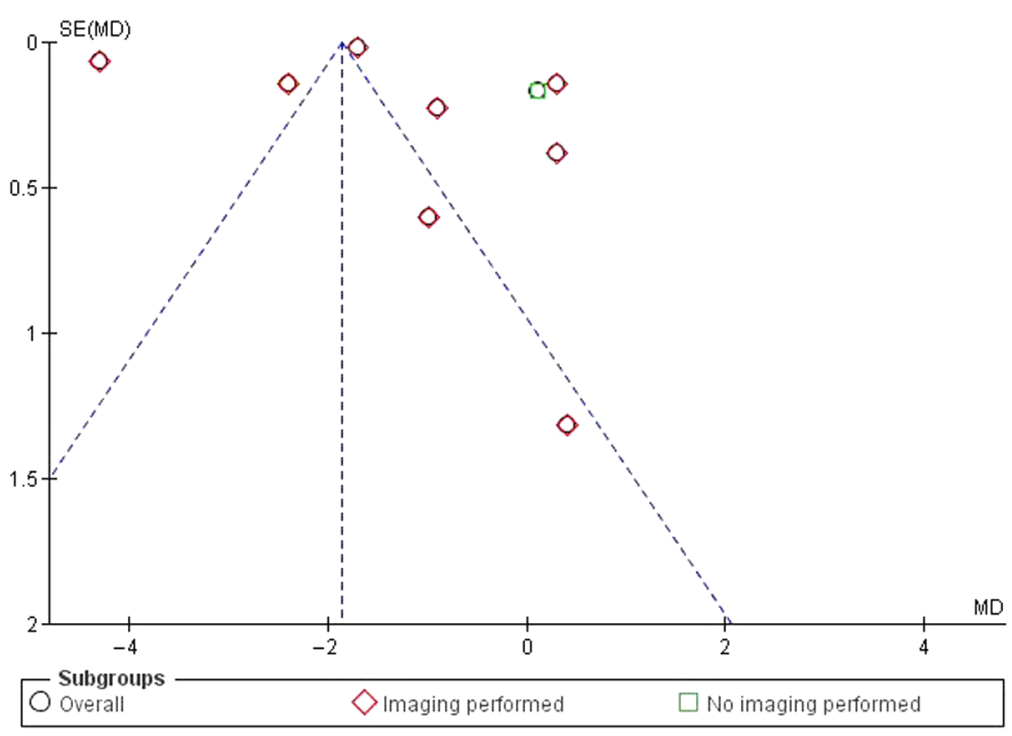

Figure 8: Funnel plot of comparison: $1 \mathrm{VP}$, outcome: 1.2 Change in pain intensity from baseline.

studies published in the English language were included due to lack of translation service for appropriate translation of studies published in languages other than English. However, the funnel plot suggests this did not result in any significant publication bias (Figure 8).

\section{How is This Different From Other Reviews?}

Multiple reviews have assessed the efficacy of vertebroplasty for the treatment of back pain from osteoporotic VCF in RCTs, ${ }^{12,32,34-43}$ with some of them including non-RCTs. ${ }^{35-37}$ These reviews showed the efficacy of vertebroplasty in improvement of pain compared to conservative management, but a systematic review of poorly designed cohort studies and non-RCTs generates only low quality of evidence in favour of vertebroplasty. The systematic reviews $^{12,34,38-41}$ that included two early sham control studies ${ }^{6,7}$ also showed the efficacy of vertebroplasty in pain improvement when compared to conservative management for osteoporotic VCFs. However, vertebroplasty did not perform better than sham procedures. This raised the possibility of placebo effect from vertebroplasty. The two early sham studies ${ }^{6,12}$ and another recent sham study $^{32}$ used sham procedure with infiltration of periosteum, which by itself could give pain relief. Thus, sham procedure was too aggressive and simulates the intervention. Another, more recent, study $^{30}$ used less aggressive sham procedure (with no periosteal infiltration). This study concluded that vertebroplasty performed better than sham procedure.

More recent systematic reviews ${ }^{32,41-43}$ with recent RCTs showed pain relief was better with vertebroplasty compared to conservative management. This was supported by our systematic review and meta-analysis of all RCTs comparing vertebroplasty with conservative or sham treatments published to date.

None of these reviews addressed patient selection based on imaging confirmation of marrow oedema, as selection criteria for the subjects. The current review showed that the improvement in pain score was significantly higher at immediate, short, and intermediate time points, when patients were selected based on imaging confirmation of marrow oedema but was lost at longterm follow-up. Studies with no imaging confirmation in their inclusion criteria failed to show any improvement in pain score when treated with vertebroplasty compared to conservative management. ${ }^{6,31}$ Our study is unique as this was the first and only one to assess improvement of pain when patients were selected for vertebroplasty based on imaging confirmation of marrow oedema. Our review confirmed that when vertebroplasty was done without imaging confirmation of marrow oedema, the patients 
may not benefit from vertebroplasty at any time point. This is likely due to multiple different sources of chronic back pain. In the absence of marrow oedema, the fractured vertebral body is less likely to be the source of pain. Hence, addressing such fractured vertebral bodies with vertebroplasty would not improve the pain score immediately or up to intermediate term. These important patient selection criteria for vertebroplasty have not been assessed in any reviews in the past.

\section{Author's CONCLUSION}

\section{Implication for Practice}

The grade of evidence, in favour of vertebroplasty for pain relief in painful osteoporotic VCF, is only moderate. Better designed RCTs are needed to prove this beyond doubts. For future RCTs as well as in routine clinical practice, vertebroplasty should only be offered in painful osteoporotic VCF in the presence of marrow oedema on imaging in the index vertebral body. Our study results may help funding applications for vertebroplasty for osteoporotic VCF in suitable patients.

\section{Implication for Research}

In the light of our review, any future trials evaluating efficacy of PVA in osteoporotic VCF should select patients only with imaging confirmation of marrow oedema in the fractured vertebral body. In our review, the evidence for efficacy of vertebroplasty for improvement in pain score is only moderate due to the biases in included RCTs. For a higher level of evidence, better designed RCT, free of all recognised biases, should be conducted and patients should only be selected after imaging confirmation of marrow oedema.

\section{Conclusions}

RCTs using imaging to confirm marrow oedema in the index vertebra showed an improved size effect compared to RCTs using no imaging. This benefit was observed in the immediate, short, intermediate and long term.

\section{ACKNOWLEDGEMENTS}

The authors would like to acknowledge help and support at different stage of this project from Dr. Jill Hayden, Dalhousie University and Dr. Katherine Atkins, LSHTM, University of London, UK.

\section{Disclosures}

The authors have no conflicts of interest to declare.

\section{Statement OF AUTHORShIP}

JJS, RM and SF - Collected data, RP - Search strategy and editing of the manuscript, JJS - Conception, data analysis and manuscript editing, and RM - Data analysis.

\section{REFERENCES}

1. Burge R, Dawson-Hughes B, Solomon DH, et al. Incidence and economic burden of osteoporosis-related fractures in the United States, 2005-2025. J Bone Miner Res Off J Am Soc Bone Miner Res. 2007;22:465-75.

2. Venmans A, Lohle PNM, van Rooij WJ. Pain course in conservatively treated patients with back pain and a VCF on the spine radiograph (VERTOS III). Skeletal Radiol. 2014;43:13-8.

3. Tarride J-E, Hopkins RB, Leslie WD, et al. The burden of illness of osteoporosis in Canada. Osteoporos Int. 2012;23:2591-600.

4. Eichholz KM, O'Toole JE, Christie SD, et al. Vertebroplasty and kyphoplasty. Neurosurg Clin N Am. 2006;17:507-18.

5. Nussbaum DA, Gailloud P, Murphy K. A review of complications associated with vertebroplasty and kyphoplasty as reported to the Food and Drug Administration medical device related web site. J Vasc Interv Radiol JVIR. 2004;15:1185-92.

6. Kallmes DF, Comstock BA, Heagerty PJ, et al. A randomized trial of vertebroplasty for osteoporotic spinal fractures. N Engl J Med. 2009;361:569-79.

7. Buchbinder R, Osborne RH, Ebeling PR, et al. A randomized trial of vertebroplasty for painful osteoporotic vertebral fractures. N Engl J Med. 2009;361:557-68.

8. Baerlocher MO, Munk PL, Liu DM, et al. Clinical utility of vertebroplasty: need for better evidence. Radiology. 2010;255:669-74.

9. Chen L, Black C, Hirsch JA, et al. Vertebroplasty trials: the medium is the message. J Vasc Interv Radiol JVIR. 2014;25:323-5.

10. Hargunani R, Le Corroller T, Khashoggi K, et al. An overview of vertebroplasty: current status, controversies, and future directions. Can Assoc Radiol J J Assoc Can Radiol. 2012;63:S11-7.

11. Baerlocher MO, Munk PL, Radvany MG, et al. Vertebroplasty, research design, and critical analysis. J Vasc Interv Radiol. 2009;20:1277-8.

12. Buchbinder R, Golmohammadi K, Johnston RV, et al. Percutaneous vertebroplasty for osteoporotic vertebral compression fracture. Cochrane Database Syst Rev. 2015:CD006349.

13. Liberati A, Altman DG, Tetzlaff J, et al. The PRISMA statement for reporting systematic reviews and meta-analyses of studies that evaluate health care interventions: explanation and elaboration. PLoS Med. 2009;6:e1000100.

14. Higgins JPT, Green S. Higgins JPT, Green S. Cochrane handbook for systematic reviews of interventions version 5.0.2. [updated September 2009]. The Cochrane Collaboration; 2008.

15. Moher D, Shamseer L, Clarke M, et al. Preferred reporting items for systematic review and meta-analysis protocols (PRISMA-P) 2015 statement. Syst Rev. 2015;4:1.

16. Ostelo RWJG, Deyo RA, Stratford P, et al. Interpreting change scores for pain and functional status in low back pain: towards international consensus regarding minimal important change. Spine. 2008;33:90-4.

17. Higgins J, Thompson S, Deeks J, et al. Statistical heterogeneity in systematic reviews of clinical trials: a critical appraisal of guidelines and practice. J Health Serv Res Policy. 2002;7: 51-61.

18. Deeks JJ, Higgins JPT, Altman DG, editors. Chapter 9: analysing data and undertaking meta-analyses. In: Higgins JPT, Green S, editors. Cochrane handbook for systematic reviews of interventions version 5.1.0 (updated March 2011). The Cochrane Collaboration; 2011. www.handbook.cochrane.org.

19. Atkins D, Best D, Briss PA, et al. Grading quality of evidence and strength of recommendations. BMJ. 2004;328:1490.

20. Van Meirhaeghe J, Bastian L, Boonen S, et al. A randomized trial of balloon kyphoplasty and nonsurgical management for treating acute vertebral compression fractures: vertebral body kyphosis correction and surgical parameters. Spine. 2013;38:971-83.

21. Li Y, Zhu J, Xie C. A comparative study of percutaneous kyphoplasty and conservative therapy on vertebral osteoporotic compression fractures in elderly patients. Int $\mathrm{J}$ Clin Exp Med. 2017;10(5):8139-45.

22. Leali PT, Solla F, Maestretti G, et al. Safety and efficacy of vertebroplasty in the treatment of osteoporotic vertebral compression fractures: a prospective multicenter international randomized controlled study. Clin Cases Miner Bone Metab Off J Ital Soc Osteoporos Miner Metab Skelet Dis. 2016;13:234-6.

23. Chen D, An Z-Q, Song S, et al. Percutaneous vertebroplasty compared with conservative treatment in patients with chronic painful osteoporotic spinal fractures. $\mathrm{J}$ Clin Neurosci Off $\mathbf{J}$ Neurosurg Soc Australas. 2014;21:473-7.

24. Yang E-Z, Xu J-G, Huang G-Z, et al. Percutaneous vertebroplasty versus conservative treatment in aged patients with acute 
osteoporotic vertebral compression fractures: a prospective randomized controlled clinical study. Spine. 2016;41:653-60.

25. Farrokhi MR, Alibai E, Maghami Z. Randomized controlled trial of percutaneous vertebroplasty versus optimal medical management for the relief of pain and disability in acute osteoporotic vertebral compression fractures. J Neurosurg Spine. 2011;14:561-9.

26. Blasco J, Martinez-Ferrer A, Macho J, et al. Effect of vertebroplasty on pain relief, quality of life, and the incidence of new vertebral fractures: a 12-month randomized follow-up, controlled trial. J Bone Miner Res Off J Am Soc Bone Miner Res. 2012;27: 1159-66.

27. Voormolen MHJ, Mali WPTM, Lohle PNM, et al. Percutaneous vertebroplasty compared with optimal pain medication treatment: short-term clinical outcome of patients with subacute or chronic painful osteoporotic vertebral compression fractures. The VERTOS study. AJNR Am J Neuroradiol. 2007;28: 555-60.

28. Klazen CAH, Lohle PNM, de Vries J, et al. Vertebroplasty versus conservative treatment in acute osteoporotic vertebral compression fractures (Vertos II): an open-label randomised trial. Lancet Lond Engl. 2010;376:1085-92.

29. Firanescu CE, de Vries J, Lodder P, et al. Vertebroplasty versus sham procedure for painful acute osteoporotic vertebral compression fractures (VERTOS IV): randomised sham controlled clinical trial. BMJ. 2018;361:k1551.

30. Clark W, Bird P, Gonski P, et al. Safety and efficacy of vertebroplasty for acute painful osteoporotic fractures (VAPOUR): a multicentre, randomised, double-blind, placebo-controlled trial. Lancet Lond Engl. 2016;388:1408-16.

31. Rousing R, Andersen MO, Jespersen SM, et al. Percutaneous vertebroplasty compared to conservative treatment in patients with painful acute or subacute osteoporotic vertebral fractures: three-months follow-up in a clinical randomized study. Spine. 2009;34:1349-54.

32. Zhao S, Xu C-Y, Zhu A-R, et al. Comparison of the efficacy and safety of 3 treatments for patients with osteoporotic vertebral compression fractures: a network meta-analysis. Medicine (Baltimore). 2017;96: e7328.

33. Guyatt GH, Oxman AD, Vist G, et al. GRADE guidelines: 4. Rating the quality of evidence-study limitations (risk of bias). J Clin Epidemiol. 2011;64:407-15.
34. Stevenson M, Gomersall T, Lloyd Jones M, et al. Percutaneous vertebroplasty and percutaneous balloon kyphoplasty for the treatment of osteoporotic vertebral fractures: a systematic review and cost-effectiveness analysis. Health Technol Assess Winch Engl. 2014;18:1-290.

35. Hochmuth K, Proschek D, Schwarz W, et al. Percutaneous vertebroplasty in the therapy of osteoporotic vertebral compression fractures: a critical review. Eur Radiol. 2006;16: 998-1004.

36. Hulme PA, Krebs J, Ferguson SJ, et al. Vertebroplasty and kyphoplasty: a systematic review of 69 clinical studies. Spine. 2006; 31:1983-2001.

37. Ploeg WT, Veldhuizen AG, The B, et al. Percutaneous vertebroplasty as a treatment for osteoporotic vertebral compression fractures: a systematic review. Eur Spine J Off Publ Eur Spine Soc Eur Spinal Deform Soc Eur Sect Cerv Spine Res Soc. 2006;15:1749-58.

38. Shi M-M, Cai X-Z, Lin T, et al. Is there really no benefit of vertebroplasty for osteoporotic vertebral fractures? A meta-analysis. Clin Orthop. 2012;470:2785-99.

39. Papanastassiou ID, Phillips FM, Van Meirhaeghe J, et al. Comparing effects of kyphoplasty, vertebroplasty, and non-surgical management in a systematic review of randomized and nonrandomized controlled studies. Eur Spine J Off Publ Eur Spine Soc Eur Spinal Deform Soc Eur Sect Cerv Spine Res Soc. 2012;21:1826-43.

40. Liu J, Li X, Tang D, et al. Comparing pain reduction following vertebroplasty and conservative treatment for osteoporotic vertebral compression fractures: a meta-analysis of randomized controlled trials. Pain Physician. 2013;16:455-64.

41. Anderson PA, Froyshteter AB, Tontz WL. Meta-analysis of vertebral augmentation compared with conservative treatment for osteoporotic spinal fractures. J Bone Miner Res Off J Am Soc Bone Miner Res. 2013;28:372-82.

42. Li L, Ren J, Liu J, et al. Results of vertebral augmentation treatment for patients of painful osteoporotic vertebral compression fractures: a meta-analysis of eight randomized controlled trials. PloS One. 2015;10:e0138126.

43. Yuan W-H, Hsu H-C, Lai K-L. Vertebroplasty and balloon kyphoplasty versus conservative treatment for osteoporotic vertebral compression fractures: a meta-analysis. Medicine (Baltimore). 2016;95:e4491. 